\title{
International Service Learning Design Projects: EDUCATING TOMORROW'S ENGINEERS, SERVING THE Global Community, And Helping to MeEt ABET CRITERION
}

\author{
Dan Budny \\ Department of Civil and Environment Engineering \\ University of Pittsburgh \\ budny@pitt.edu \\ Robert Thomas Gradoville \\ Department of Civil and Environment Engineering \\ University of Pittsburgh \\ rgradovi@gmail.com
}

\begin{abstract}
International service-learning projects are an effective educational tool for universities striving to meet the ABET engineering criterion, while also providing transformational experiences to their students and a service to needy populations in the world. This paper discusses the benefits of international service-learning projects for students, the international community, and the university. The year-long process of development and piloting of the first international humanitarian engineering servicelearning project within the Pittsburgh Department of Civil Engineering is presented. Also, the ABET engineering criterion are then discussed, with specific attention to the criterion that are harder to address with traditional engineering education. This pilot project was a collaboration between the senior design course, a local chapter of Engineers Without Borders, and various domestic and international entities. The benefits of international service learning projects are discussed, in the hopes of catalyzing development of similar projects in the future.
\end{abstract}

Index Terms - Cross-cultural understanding, Service Learning, Senior Design, Engineering Education.

\section{INTRODUCTION}

International service learning projects are becoming more popular in engineering higher

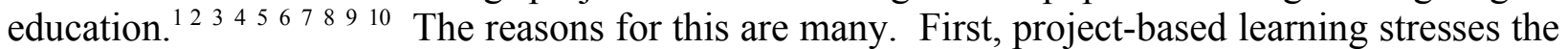
importance of teamwork in engineering design. ${ }^{11}$ Today's engineer will most likely be in contact with not only engineers from other disciplines, but also with additional technical and nontechnical professionals as well. The inherent cross-disciplinarity of project-based learning allows for practice in communication, working in a group under timeline constraints, and 
International Journal for Service Learning in Engineering Vol. 6, No. 2, pp. 98-117, Fall 2011

ISSN 1555-9033

provides students with a sense of accomplishment and competence upon completion of the project. Project-based learning also usually involves a "client" to whom the student engineers will be held accountable. This can teach fourth year engineering students, that sometimes satisfying a non-academic client involves social skills that have not been called upon previously. As the world becomes more integrated, engineers and technologists are called upon to weigh the costs and benefits of disparate considerations. Project-based learning forces students to reconcile sometimes seemingly irreconcilable priorities, thus preparing them for their future careers and personal lives. Additionally, project management skills developed in the process are invaluable for all engineers as they proceed along their career paths.

Providing all of the benefits of project-based learning while additionally providing services to the local community, service-learning has been proven as an effective method of teaching engineering design. ${ }^{12}$ The process of serving others is a hands-on way to achieve deep learning. The University Pittsburgh has experience in this movement, with the honors freshmen engineering course Engineering Applications for Society. ${ }^{13}$

International service learning can take the analytical skills of engineering students to places in the world where help is most needed. For example, there are lesser-developed countries in the global South that contain many small villages that are still in need of the most basic services, such as clean water, sanitation, educational facilities, and basic healthcare. Over the past decade higher education has awoken to the transformational effect experiences abroad can have on college-aged students. For this and other reasons, many engineering programs have expanded their international reach, focusing on the theme of globalization and its effect on engineering in the future. While this is a valid and pertinent subject in the contemporary industrial world, affecting the competitiveness of job placement for graduating engineers, the University of Pittsburgh has become interested in the flipside of the equation. Small, marginalized populations in the world that do not have the most basic levels of education and infrastructure are being left behind. Technology has marched on in tune with the priorities and funding provided by the most advanced countries. Thus, the needs of the "bottom billion", the poorest people on this earth who are living on just dollars a day, are largely neglected. ${ }^{14}$ A lot can be learned by providing engineering services to the poor, both by the students and the locals they serve. International service learning has thus emerged as a practical, necessary, morally and ethically responsible way to engage engineering students in the work of engineering.

This educational approach can produce an interesting debate: that although international service learning is very beneficial to the students involved, do the community recipients of the projects receive the same benefit. Entire books have been written to discuss these issues ${ }^{15}{ }^{16}$, and critics can argue that this serves to reinforce unequal power relations between the global North and South. The potential for this outcome is real if the university faculty and additional partners involved do not ensure, from the beginning of the project, that the outcomes of the course are clearly stated to the partner community. This allows for accountability, giving the community the ability to ask why certain stated outcomes were not achieved, if that becomes the case. Nevertheless, the authors wish to present an alternative point of view. 
International Journal for Service Learning in Engineering

Vol. 6, No. 2, pp. 98-117, Fall 2011

ISSN 1555-9033

A disparity in the amounts that students and partner communities benefit is not a welldocumented phenomenon. The students and faculty involved may learn a lot over the course of the project, as this is something they can personally attest to. Nevertheless, the lack of benefit imparted to the community is not as easily measured. It is true that from an engineering perspective, sometimes projects of this sort fall short of their goals in providing, for example, a 20 -year supply of potable water or a sanitation system that will solve the problems of poor hygiene found in the area. Although these cases should clearly be avoided, as the engineering goals are of primary concern, this does not mean that the communities have not benefited greatly. The author can attest to this statement, having worked on similar projects in a village in the Dominican Republic for two years as a Peace Corps Volunteer. The partner communities involved in these projects are asked to organize themselves in a way that may facilitate progress in the village. This may not be seen as a major benefit to students in the North, as our culture is structured rigidly around rules and bureaucratic organizations, but many cultures in developing countries lack this most basic first step. In many cases, lack of organizational capacity precludes future development and community progress. Therefore, partnership of a village with a university group or engineering organization can have transformative effects on their future ability to help themselves. As the author can attest to, $100 \%$ successes in community development projects are scarce or possibly non-existent. Even when projects are implemented by some of the largest and most reputable organizations, such as the United States Agency for International Development (USAID), setbacks and unique challenges of operating in another country are ubiquitous. Improvements for successful implementation of these projects are always needed, but this should not serve to discount the value of international service learning to all parties. Rather, this should serve as a call to action for more engineering universities to report on their successes and failures, as to improve the efficiency and impact of projects of this sort.

As the impact on the community is much more difficult to measure, and is not of prime focus here, the impact on the students involved will be discussed to a greater depth in this article.

\section{The VAlue For Students}

Students benefit in different ways from different aspects of the coursework. The project aspect provides real-world experience and a concrete starting and ending point, simulating the realworld project implementation experience. The service-learning aspects introduce the concept of engineering as a tool for helping society, the importance of understanding customer needs, and introduce an invaluable depth to the experience of engineering. An international experience early in the professional career is exciting and stimulating, as the most basic assumptions in our daily lives are challenged, including those concerning language and culture. Those moments, when students' senses are peaking, are opportunities for transformational educational impacts that can have ripple effects on their future lives and careers. 
International Journal for Service Learning in Engineering

Vol. 6, No. 2, pp. 98-117, Fall 2011

ISSN 1555-9033

\section{Project-Based Coursework}

The benefits of project-based coursework have been well-documented. ${ }^{17} 18192021222324$ Project based learning can help to develop the higher order critical thinking, life, and self-management skills that are so important for any young adult. The project format also allows students to more actively engage in learning, delve deeper into an issue, makes the content more meaningful, and is an effective way to engage multiple different learning styles into one project. Students are empowered to take initiative and responsibility for their own learning, and ultimately make critical choices as to which part of the project process they wish to explore. ${ }^{25}$ One of the key elements of project-based coursework and employment in the engineering field is interaction with and accountability to a client. Designing to satisfy the needs of a client, reporting information clearly to keep your client updated on progress, and dealing with changes requested by the client are all integral parts of the project cycle. When that client is located overseas, in a country that speaks a language you have not mastered, the challenges multiply. Our students have shown, again and again, to rise to these newly introduced challenges and gain a sense of accomplishment that a traditional lecture-based course cannot match. Additionally, projectbased learning promotes the development of project-management skills, teamwork, and the ability to effectively schedule around other commitments. These life-skills are important to any working professional, but specifically the engineer of today. As globalization and technical competitiveness are changing the landscape of the job market, a new approach is needed to train these engineers. ${ }^{26}{ }^{27}$ Project-based learning has consistently been shown to be one of the most effective strategies for this purpose.

\section{Service-Learning}

Benefits of service-learning to students involved are less documented, as the phenomenon of service-learning has grown out of the project-based learning paradigm, but practitioners of service-learning have become convinced it is an effective tool in many aspects of engineering education. Over the years researchers have been garnering evidence of the short and long-term benefits of service learning ${ }^{28}{ }^{29}$ and urging its addition in standard teaching curriculum. Service learning has a distinct advantage over traditional teaching techniques in that it adds two additional elements to the obvious goal of learning course content: the local community is served by students, and those students are then forced to reflect on the connection between the course educational objectives and the experiences they had in the field. Education ultimately is meant to produce positive results for society as a whole, and this point is inherently reinforced through the service-learning experience. Combining learning and service objectives ensures that both the community partner and the students providing the service receive benefits from the interaction. In a lucrative field such as engineering, service learning is one opportunity for students to give back to their local community, learn a lot about the personal and moral merits of service, and gain a better understanding of the struggles that underserved populations encounter. Engineering 
International Journal for Service Learning in Engineering Vol. 6, No. 2, pp. 98-117, Fall 2011

ISSN 1555-9033

as a field was developed to respond to the needs of the community, and service learning provides an experiential framework for this. ${ }^{30} 313233$

\section{International Exposure}

International exposure for students has never been easier, more relevant, or more commonplace in the field of higher education. Across the country educational programs are stressing the need for international travel and some are starting to require this as a graduation requirement of their students. $^{3435}$ This is not to say that local service learning is invaluable, only that the benefits of an international experience are unique. Focusing internationally is a break from the traditional domestic engineering project and meant to expand the horizons of the students involved. This concept and our results will be further addressed in this study. The reasons for doing this are obvious for the engineering student. First, students get a chance to partner with international entities, thus preparing them for their future careers. Second, students will gain exposure to international design codes and standards. A familiarity with the different ways that engineers operate across the globe is an important skill set. Third, students will get to experience the global working environment. Simply having an overseas experience has the potential to drastically alter what students see as their career path. The benefits of international exposure, in terms of understanding engineering in a global and societal context cannot be over emphasized

\section{Differing FrameWorks For Providing InTERnational SERVICE-LEARning}

As with any educational program, there are many techniques developed for the delivery of international service-learning. Each university hoping to add international service learning projects must assess the capabilities of their department, the specific learning outcomes they are striving for, and select which framework will work best for them. ${ }^{36} 3738394041$

There are two main choices that must be made when designing an international servicelearning program. The first is the length of time you wish to spend working with students on the project. This can vary from as short as a week to two full semesters or longer. The second is whether or not you plan to bring the students to the overseas location. The international trip can add many layers of complexity to the project planner, but has consistently been shown to be the most memorable part of these projects to the students involved. It is memorable not only because overseas travel is necessarily something that students do not engage in very frequently, but also because of the impact of seeing, first-hand, the context within which they have been

designing, has a really deep impact on the students involved. This is related to the effect of experiential learning on students. ${ }^{42} 43$

When designing an international service-learning project a decision needs to be made as to the length of the course/experience. Some of the first attempts at service projects were undertaken as "mission-style" trips to distant lands, engaging students in physical labor and/or simple construction projects. These projects are easy to plan, have very palpable payoff in terms of student satisfaction, and provide a service where one is needed. Conversely, they have the lowest educational impact on students. The longer and more in-depth the service learning 
International Journal for Service Learning in Engineering

Vol. 6, No. 2, pp. 98-117, Fall 2011

ISSN 1555-9033

experience, the greater impact it will have on all students involved. Additional project length also creates opportunities for vertical integration of students from different age groups and development of leadership skills. ${ }^{44}$

The various frameworks of international service learning project can be broken into three categories, although new techniques are emerging constantly. One style advocates the pairing of students from the US with students from another country by means of telecommunication, sometimes making use of video teleconferencing if available. Another is to send US students to a foreign country, collect data, and return home to complete the engineering design work that is necessary. A third is to acquire necessary data, or produce realistic although theoretical data, which can be used by students in the US to move through the necessary design process. This has been described as the "stay at home" service learning project. All options involve international service-learning, but have pros and cons associated with each.

There are various benefits and drawbacks associated with each of the options regarding project length and project style. The two obviously are not mutually exclusive to any extent either, as the cost and design of a semester-long program will be very different if it is undertaken overseas, in the US, or with a shorter planned immersion trip. Nevertheless, the general merits of decisions made regarding these two important factors will be discussed.

The length of the international service learning experience will affect, to a large extent, the degree to which students retain the knowledge imparted by the experience. Gains in expanding the student's perception of international issues can be observed from both methods. As the phrase goes, practice makes perfect and the longer the experience the more time students will have to absorb the information that is directed at them. This has been the experience of the authors, both previously as a student involved in a service learning experience and as planners in the delivery of the project that is the focus of this paper.

One of the benefits to shorter service-learning experiences are that they can be more easily integrated into an existing curriculum, require less manipulation of the standard course structure, and rely less funding. It is for this reason that the project described in this paper uses this method. By using semester breaks such as the holiday break between semesters and spring break, short trips can be included into the curriculum without the need for the students to miss other class during the semester. Short term experiences may be a good way for universities to start down the road towards longer term projects, and, as student feedback comes in, it may become evident that the students themselves will request more and more service projects.

The different frameworks of international service-learning projects also have their own advantages and disadvantages, largely associated with the communication challenges each will present. In a joint venture between US and foreign students, there are many added benefits including: the increased pool of technical skills, experience gained in communicating across cultural boundaries with modern technology, an accurate representation of the way many transnational engineering efforts are undertaken, and the possibility of an international experience for those students or academic programs that cannot afford to travel internationally otherwise. This style of project is possibly one of the easier models to follow, as modern forms of communication and translation make contacting student peers in another country just a few 
International Journal for Service Learning in Engineering Vol. 6, No. 2, pp. 98-117, Fall 2011

ISSN 1555-9033

clicks away. Nevertheless, this model of partnership has some disadvantages: partner universities must acquire compatible communication technologies and become proficient in their use, the design process is complicated by the inability to share information in many forms at the same time (i.e. no physical interaction between team members), and this style of partnership demands a lot of the coordinating faculty members. The other technique of sending US students through the university Study Abroad offices, to a foreign country for part or all of the project length is arguably the most popular, and for good reason. The face-to-face contact that students have with their foreign counterparts is invaluable. The hands-on experience gained from physically seeing and doing part of the design process is a bonus. Also, this introduces a real project timeline with concrete deadlines that must be met, within the semester timeline. Unfortunately, this type of experience is more expensive than others since international travel is required and the students must leave their campus life and move to a new location. Also, this model produces a scenario where the advisor can lose control over the learning experience if they themselves are not experienced in similar real-life project work. Lastly, this model puts significant strain on the host partner just before, during, and after the trip. Many preparations need to be made for accommodation of US college students, and the logistics involved can be daunting. This model requires a faculty advisor confident with handling complex logistical scenarios and adapting to changing situations on the fly. The last model, the stay-at-home service learning project, is a good option for universities that can access all the necessary data for an overseas design project, but are not sure about the logistics of coordinating with a project partner, or of traveling on an international trip. This model is most similar to domestic design projects. It is easier to implement, but many of the project management skills bred out of necessity of working with a project partner will be missed.

\section{Demand For International Service-Learning Projects From Students}

Engineering students nowadays seem to have a passion for serving the needs of the poor in the world. Organizations like Engineers Without Borders (EWB), Engineers for a Sustainable World (ESW), and Engineering World Health (EWH) have sprung up and expanded rapidly over the past decade. These three non-profit organizations have volunteer student chapters at universities all over the United States. All three organizations simply provide a framework and outlet for the aspirations of young enterprising engineering students, those who have a strong desire to help underserved populations throughout the world. Research is currently underway to help determine why so many students seem to be drawn to service, and what specific characteristics of engineering students are most closely correlated with a desire to serve. ${ }^{45}$ Part of the reason may have to do with generational differences between engineers today and in the past. Additionally, this may have to do with the global sustainability movement, and the awareness of the interconnectedness of all nations on the planet and the environment. Whatever the reason, it is clear that the demand for international service learning projects is increasing among the college-aged student population. 
International Journal for Service Learning in Engineering Vol. 6, No. 2, pp. 98-117, Fall 2011

ISSN 1555-9033

\section{DESCRIPTION OF COMMUNity PROJECT: Tingo PUCARA WATER SUPPLY}

Over the course of a spring semester, fourth-year civil engineering students were involved in an international service-learning project in a small village in Ecuador, Tingo Pucara. The author, involved in an Engineers Without Borders to accomplish this task, enlisted the help of engineering students to complete the task in a timely manner. Tingo Pucara is an indigenous community located in the province of Cotopaxi, in the central highlands of the Ecuadorian Andes. At nearly 13,000 feet in elevation, this has been described as the poorest region in Ecuador, with indicators for poor health, few employment opportunities, dry and mineral deficient soil resulting in undernourishment, and lower literacy rates than most other areas of the country. The village of Tingo Pucara was formed in 1996 after an earthquake left a large number of families of the region homeless. The villagers came together and formed a new community. Since then they have organized themselves, formed a water committee, and have tried to secure technical support and funding for the design and construction of a potable water system in their community, which they have identified as their principal priority.

In 2008 the Pittsburgh Professional Chapter of Engineers Without Borders (EWB) took on the design and construction of this system as their main project. Then, in the fall of 2010, the decision was made to divide the system into two projects: one project, to pump water up a mountain to a storage tank, would be the responsibility of EWB, and the other, to design a distribution system to bring water to each of the 26 homes in the village, would become the senior design project for the Civil Engineering Department. This decision was made to speed up the design process and therefore comply more efficiently with requests from possible funding sources for a complete engineering design. EWB members, as well as villagers from Tingo Pucara had previously received interest from funding sources, therefore, time was of the essence.

\section{COURSE GoAls ANd OBJECTIVES}

The University of Pittsburgh has offered a domestic service-learning course to freshmen engineering students for over 5 years. This course aims to expand the current freshman service learning opportunities offered at the University to include upper class students, the international community, to expose our students to the challenges of working in a different cultural and economic context, and to provide support to communities in need in Ecuador. The goal of this project was to create a new course connected with the Civil Engineering Senior Design class that would allow students to gain experience in engineering design, project management, issues of constructibility in a resource-constrained environment, and the impact that different cultural and historical considerations have on engineering designs. Additionally, they will gain a renewed sense of the urgency and need for qualified engineers, not only in the traditional industrial setting, but also for on-going humanitarian efforts throughout the world. In this way, they will be exposed to the fields of international development and humanitarian engineering. This course will also have a significant impact on the beneficiary communities in the obvious health and 
International Journal for Service Learning in Engineering

Vol. 6, No. 2, pp. 98-117, Fall 2011

ISSN 1555-9033

hygiene improvements that come with clean water. This project will also benefit international governments that are lacking the engineering expertise and human resources to provide such basic services to the populace. The need for a new course number is based on the requirements of proper safety and other concerns that the university has related to travel abroad. Travel abroad can bring in a number of legal issues and by separating the travel and logistical issues into a separate course, you can couple the existing senior design course with the study abroad course and meet the needs of both the academic setting and the legal requirements.

For this study the senior design project is the design of the water distribution system complete with designs for family wash-basins. The distribution network, different pressure zones, and individual tap stands formed the bulk of design issues. Specific considerations included:

- The final design had to be the most cost-effective design possible, as funding for construction was limited and repairs in the future would be undertaken by members of the community water board.

- An emphasis was to be placed on appropriate technology. Where an advanced technology and a more common one were plausible alternatives, both were to be weighed on their individual merit, given the specific application.

- Static pressure heads at all faucet locations would not to exceed 50 meters. At no point would the pressures exceed the rated pressure of piping available in Ecuador.

- Where possible, looped system designs would be utilized to balance pressure fluctuations due to variations in demand.

- Hazards such as high erosion areas, walking paths, dirt roads, etc. were to be avoided and crossed only if necessary.

- The final design would be sufficiently sized to incorporate capacity for expansion of water services to the nextdoor village of Guangaje.

- Availability of all materials locally, at least at the country level, was a necessity.

- The final task given to the engineering team was to produce an entire construction plan for their water storage and distribution system.

\section{RESULTS}

Although logistically complicated, the student engineers succeeded in completing all of the above requirements. In addition, the students traveled to the site over the spring semester to oversee the commencement of construction of the project, in collaboration with in-country project partners.

To understand the benefits of traveling to Ecuador as part of this project, a small survey was given to each of the eight $(n=8)$ senior engineering students to fill out before and after the trip. One interesting result of the surveys came from the ranking of technical and non-technical terms in order of importance for "a successful completion of the senior design project."

The students were asked to rank the following 20 terms from 20 highest to 1 lowest:

1) Teamwork,

2) Sound Engineering Judgment,

3) Clear Communication,

4) Contact with local people in the village,

5) Efficient project management, 
6) Availability of local materials,

7) Grasp of local construction techniques,

8) Understanding of local economic constraints,

9) Understanding of local daily lifestyle,

10) Input from local people on the engineering design,

11) Input from local people on the construction schedule,

12) Input from local people on the operation and maintenance concerns,

13) Spanish-speaking ability,

14) Ability to work with limited data,

15) Ability to compare technological options based on engineering efficacy,

16) Ability to compare technological options based on upfront and continuing maintenance costs,

17) Ability to compare technological options based on familiarity of the locals to the technologies,

18) Understanding of local history and politics,

19) Understanding of appropriate technology,

20) Solidarity/Empathy for the locals and their current situation.

The results of the pre and post trip surveys can be seen in Figure 1. As remained constant before and after the trip to Ecuador, the group ranked teamwork, clear communication, and sound engineering judgment as their top three most important terms, respectively. In fact, all of these terms remained just as important or became more-so as a result of the trip to Ecuador, suggesting that the experience of working with their hands reinforced the importance of these terms. This is important to note, as engineering students today are recognizing that collaboration and the ability to communicate ideas are crucial skills.

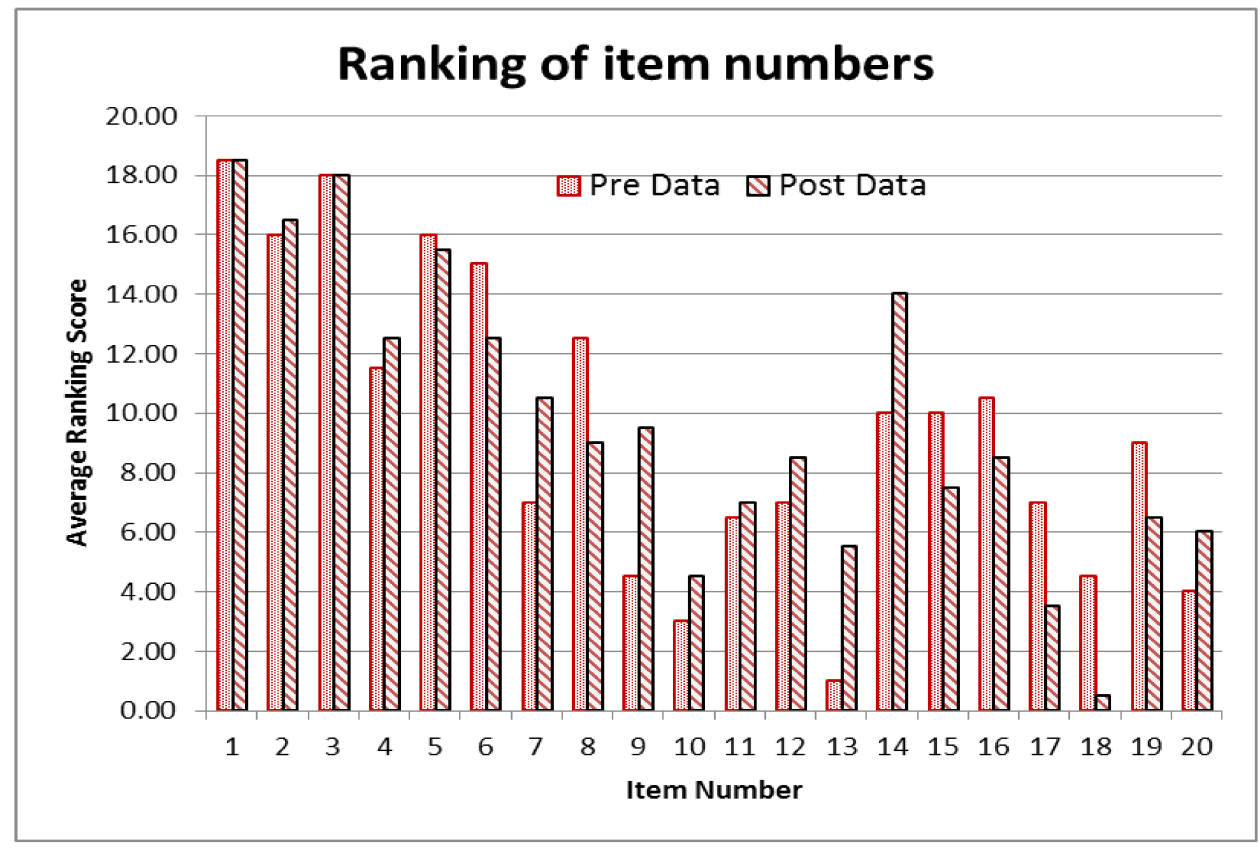

FIGURE 1:

EFFECT OF ECUADOR TRIP ON STUDENT RANKING OF TERMS 
After the trip to Ecuador, the terms that had the largest positive change in importance were: 9) understanding of local daily lifestyle, 13) Spanish-speaking ability, 14) ability to work with limited data, 7) understanding of local construction techniques and 4, 12, 11, 20, 10) the items dealing with working with the client. Figure 2 shows the gains for these items. The emphasis that the students put on these terms after the trip to Ecuador is likely only possible through an immersive experience such as international travel. The importance of Spanish, effectively the ability to communicate in Ecuador, is something that would not have been so starkly clear had the students simply designed the distribution system, and had not traveled. Additionally, recognition of the importance of the ability to work with limited data is something that all senior design capstone projects should strive for, and this became starkly clear for the students working beyond their cultural norms and language.

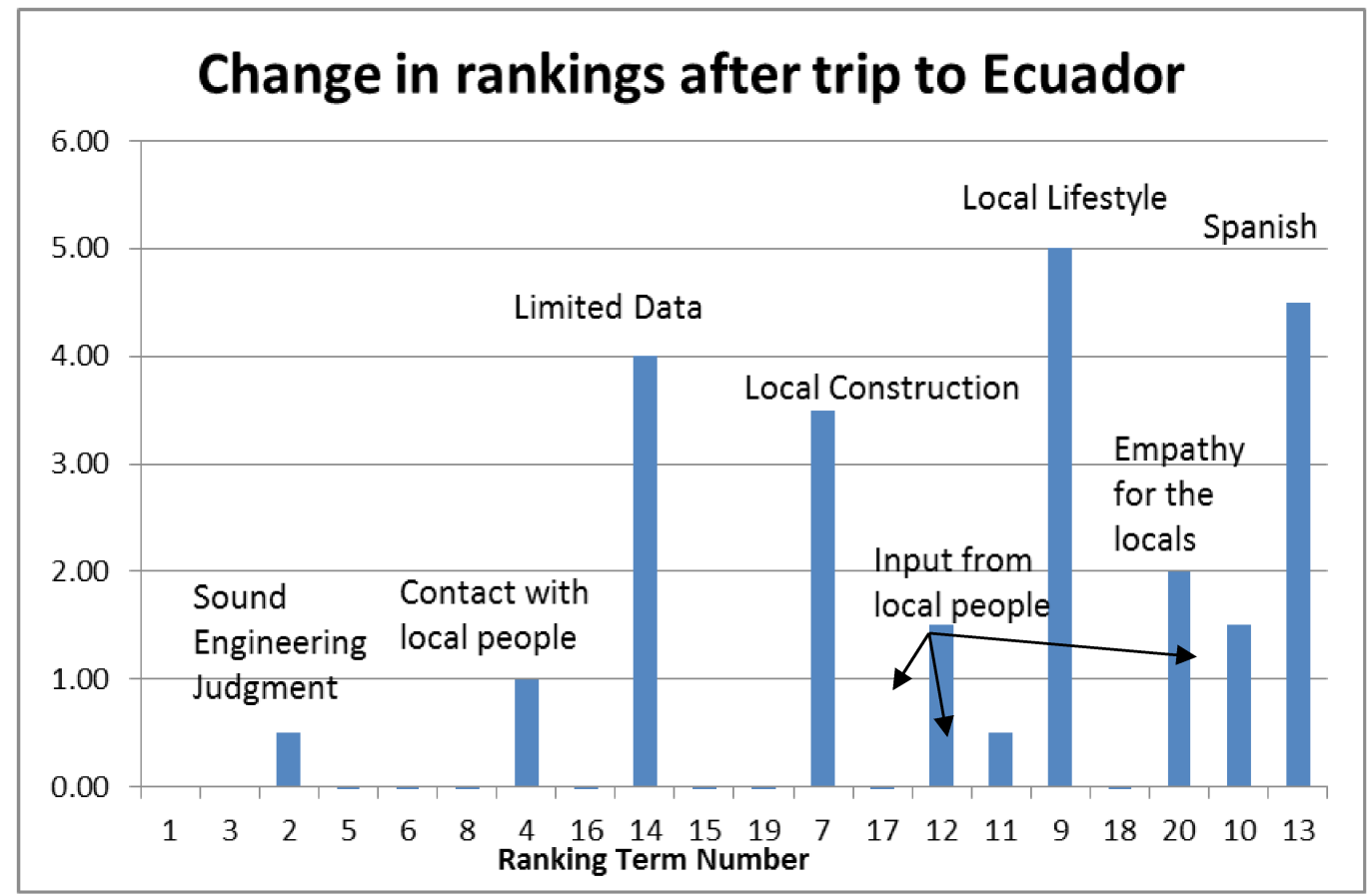

FIGURE 2:

POST TRIP STUDENT RANKING OF TERMS

For a project aimed at service-learning, it is an extremely interesting finding that the importance engineering students put on "an understanding of the local daily lifestyle" of the people they intended to help, increased significantly. Out of a field of twenty terms, the understanding of local daily lifestyle moved up 5 spots, on average, for the students who traveled on the trip. For one student, this term moved up a full 11 spots. In a field such as engineering, it is sometimes tempting to assume that design is transcendent of culture, language, and location on the planet. Regardless, in community development projects, understanding the local daily 
International Journal for Service Learning in Engineering

Vol. 6, No. 2, pp. 98-117, Fall 2011

ISSN 1555-9033

lifestyle can drastically affect the constraints placed on the engineering designs, and thus have a major impact on the resultant sustainability of the designed solution. This project, and specifically the trip to Ecuador, made this fact clear to the students involved.

In addition to the pre and post trip surveys, a brief survey was given to all 45 fourth year civil engineering students working on a senior design project. The survey, below, offered the chance for students to voice the educational effect of their senior design projects on the specific objectives of ABET.

Questions for all CEE Senior Design Teams:

1) How much has your senior design experience enhanced your understanding of professional and ethical responsibility?

2) To what degree has your senior design experience enhanced your ability to communicate effectively (both written and visually)?

3) To what degree has your senior design experience enhanced your understanding of engineering in a global and societal context?

4) To what degree has your senior design experience increased your knowledge of contemporary issues in the world?

5) How confident are you that you can complete a design within realistic constraints such as economic, environmental, social, political, ethical, health and safety, manufacturability, and sustainability?

6) Compared to your previous undergraduate coursework, how educational was your senior design experience overall? ( 0 Not at - 10 Very much)

7) Upon graduation and searching for jobs, within the continuum below, you hope to find a job that:(0 Is financially secure - 10 Is important to me/useful to society)

The results of this survey were illustrative of the strengths of international service-learning projects. Of the five different senior design projects that were offered this year in the civil engineering department, the water delivery project in Ecuador (International Travel Team) faired very well.

Figure 3 shows the Ecuador water project in comparison to the average of all senior design projects in the spring semester of 2011. As can be seen, the Ecuador project was just as good or better in all categories, when compared to the typical senior design project. Of particular interest, the Ecuador project was starkly superior to other projects in addressing an understanding of engineering in a global \& societal context, as well as an understanding of contemporary issues. Of all of the results, the greatest variance was found in those that address ABET outcomes $\mathrm{C}, \mathrm{H}$, and $\mathrm{J},{ }^{46}$ the ability to design within realistic constraints, the appreciation of engineering in a global/societal context, and a knowledge of contemporary issues, respectively. This is partly a result of the general nature of the topics addressed, but also an indicator that certain types of projects enhance the learning experience of students. This matches intuition that a project focused outside of the United States would have an impact on the view of students involved on these two topics. The students eyes were opened to new parts of the world, and new 
social problems that they hadn't considered previously. Another important finding is that the last category, "altruism", which was a measure of how likely students were to choose a job that benefits society over one that pays well, showed that members of the Ecuador team were more likely than the average student to act in an altruistic manner. This would support a claim that exposure to poverty and developing countries encourages engineers to use their skills for the betterment of humanity. All educational institutions are implicit in the general betterment of society, and programs that push students to use their skills in pursuit of social benefit rather than simply personal economic enrichment should be expanded. Although service to society has not been explicitly defined as an outcome of ABET, it is something that education professionals should value. A last finding that is not surprising is that there was an incremental improvement on all outcomes by the members of the Ecuador team that traveled in February. This supports the theory that active experiential learning is an effective tool in teaching students about social science issues.

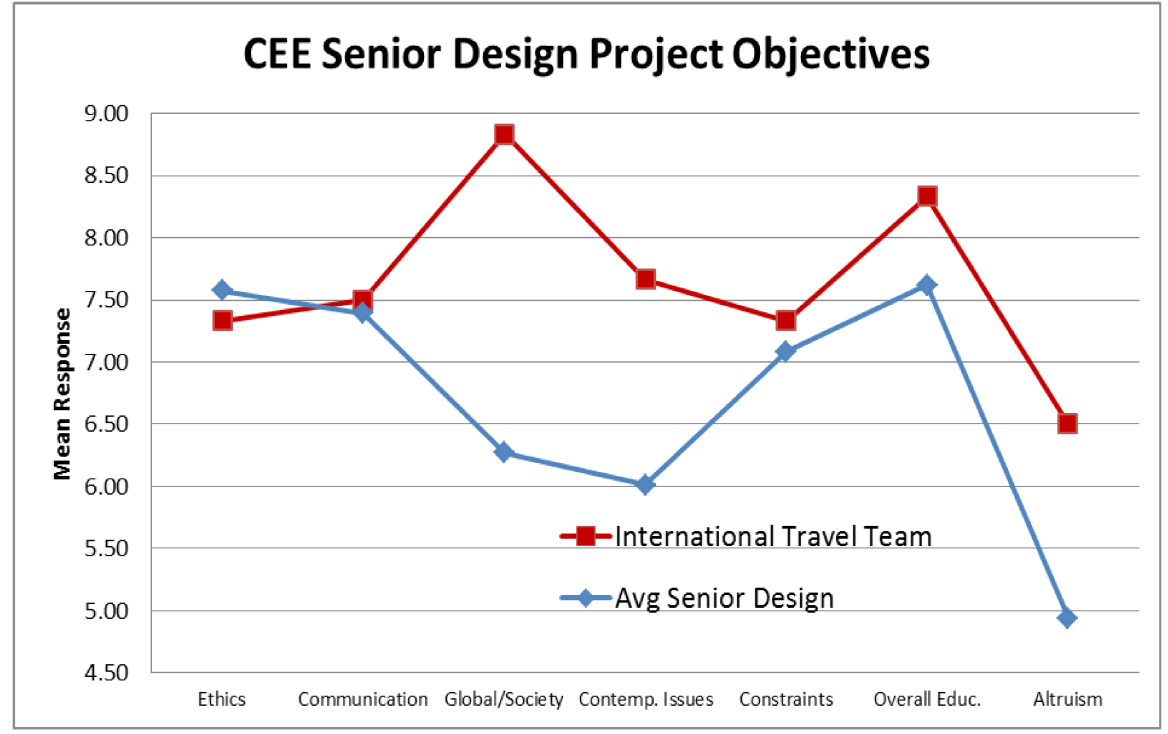

FIGURE 3:

STUDENT IMPRESSION OF SENIOR DESIGN ACCOMPLISHMENTS

Reactions from students that traveled to Ecuador are also important to note. Much of the survey was open-ended and allowed students to elaborate on topics that they felt were worthy of extra comments. Some of the most noteworthy comments have been included below.

Responding to the question, "Is this project meeting your expectations thus far", one student commented:

"Yes, we were able to collaboratively design and construct a water distribution system in another country. Working on an international project requires more logistical coordination and care, but this proved to make the project more interesting for me. Most importantly, the group now has the experience of going through the many phases of a project. We had to work with 
International Journal for Service Learning in Engineering

Vol. 6, No. 2, pp. 98-117, Fall 2011

ISSN 1555-9033

several sets of people including each other, Tingo community members, Builders Beyond Borders, and Peace Corps Volunteers. All of these people had a different type of knowledge of the project, whether it was cultural, technical, or construction related. It was exciting to be surrounded by so many motivated people and to contribute on a project that will improve the quality of life for a community."

Another student commented:

"The fact that we got to travel to see our design being built exceeded my expectations and was the best part of this project."

This project also exposed students to the world of international development and humanitarian assistance. When asked, "Do you understand poverty and international development more, less, or the same as before this project", selected student comments were: "More - I understand that it takes a lot more work than just putting money into a region or village. This community has had projects in the past that were not designed well and ended up being a waste of money. It takes more than that, it takes hard work and correct designs to really help a community develop."

When asked if this project has altered what they see as their future career path, some student responses were:

"Yes. I hope to continue working on service projects with EWB or related groups."

"Potentially in the future, I could see myself working on similar projects as this one."

Finally, all students had a very positive overall impression of this initial attempt at an internationally focused service-learning senior design project. The following is a sampling of final thoughts on the project from students who traveled to Ecuador:

"It is an amazing project, I am so grateful for the opportunity to take part in this project."

"A great experience. It's amazing to get to design something and then go build it. It's an even added bonus when what you are doing is making such a difference in people's lives, people that currently have to work so hard just to get by. It is an everlasting experience, to hear the villagers say you will go down in their history (books) for what you did."

"Purely awesome."

These comments are just a sampling of the responses from eight senior engineering students that were given the chance to use what they had learned over the previous four years to ease the suffering of villagers in Ecuador. Not only were they involved in a technical engineering problem that involved project management and communication skills that they had previously not found as crucial inside the classroom; they came away from the experience feeling truly satisfied with their efforts and confident for the future. 
International Journal for Service Learning in Engineering

Vol. 6, No. 2, pp. 98-117, Fall 2011

ISSN 1555-9033

\section{Why INTERNATIONAL VS LOCAL SERVICE LEARNING?}

This question was not part of the original study but became an interesting question as the semester ended. The construct of this international design project was no different than the design of the other five senior design projects. In fact one of the other projects was thousands of miles away on the other side of the United States. All six student design teams attended the same weekly senior design class meetings and all six produce the same reports and gave similar oral presentations. All six were equally complicated and required the same amount of engineering design calculations. So why is there such a big difference in the student attitudes as shown in Figure 3? We tried to answer this question by holding a focus group session with a number of students from the various groups. The data is very preliminary and more research on this one topic will be incorporated into future work, but the basic answer is the students felt that the international project was real and the other projects were just detailed homework assignments. The student perceptions are that because of the liability laws in the United States, nothing they do as part of a course will ever get built. Maybe it will become part of a study but before anything gets built a professional design firm would have to get involved. However, the international team knew what they put on paper was going to get put into the ground. This made the experience real for them.

\section{PARTNERShips}

This course was a success but to create such an experience requires a commitment from the University and students to take on the task. This project started as a EWB project and when the EWB team realized they needed assistance, they reached out to the faculty in the Civil Engineering Department. The senior design project was able to complete the design but without the preliminary survey work performed by EWB it is doubtful that this task could be completed in one semester. Thus, having a partner such as EWB can greatly improve the chance of success. Before the task became a senior design project the university had to perform an assessment of the site to assure the site was safe and the project was manageable. Thus, in the fall the faculty member in charge had to make a trip to the site. This was funded by the Sustainability Center at the university. The community of Tingo Pucará provided much needed organization to the project and was willing to support the project. It is clear that without local support international projects would be very difficult to perform. Another very important in-country project partner was a US Peace Corps Volunteer stationed in the area. This trustworthy local contact was instrumental in communicating with Tingo Pucará, planning trips to the area, securing local materials and maintaining community participation. Finally, we needed the assistance of the local Ecuadorian government and a nonprofit organization to assist with the funding of the construction materials, without which the construction would have been impossible. Thus, it is suggested that before an international service learning project is started you should make sure the proper resources are available to complete the task. 
International Journal for Service Learning in Engineering

Vol. 6, No. 2, pp. 98-117, Fall 2011

ISSN 1555-9033

\section{SUMMARY}

An international service-learning project provides students with a unique, challenging and rewarding educational experience. Students strongly value projects that are of importance to others in need while also being challenging. Offering projects of this sort have been shown to increase the likelihood of student satisfaction and their continued involvement in community service. In addition, the service learning experience can expand the students' perspectives regarding their potential value as engineers and the skills that are required to successfully complete a "real world" engineering project in a team environment. Such skills as how to work in and function as a team, how to communicate professionally, and how to manage a project are not as emphasized in traditional engineering courses. Furthermore the value of such skills is difficult to impress upon students unless they are able to experience the need to learn and develop them first hand, as is the case with service-learning projects.

An engineering service learning course has a multidimensional set of additional benefits above and beyond those observed using traditional problem based learning. The challenges the students encounter in their service learning projects are more consistent with those that engineers are faced with in the professional workplace (the "real world"), and furthermore, the students are motivated to overcome the difficulties they encounter by nature of the project being a real problem whose solution is of value to a community organization. In addition to the students, there are other beneficiaries of a well-organized service learning course. The university itself also benefits in the strengthening of the relationship with the community partners, and the engineering program benefits by offering an innovative educational program which addresses specifically the objectives and program outcome criterion set forth within the ABET Engineering Criteria. Additionally, these projects help demonstrate what the engineering process is all about and teach students that the primary role of engineers is to serve the community.

This pilot project showed that there are educational benefits to be had by offering international service-learning projects to engineering students. Many aspects of the ABET Engineering Criteria are addressed in this international project format that would be difficult to address with substance by other methods, as was evidenced by this projects superiority in terms of a global and contemporary focus. This project is unique with regards to similar international projects of it's sort in that it addressed a specific engineering need identified by exceptionally poor villagers in Ecuador, and successfully provided a solution in collaboration with the village, the Ecuadorian government, the US Peace Corps, Engineers Without Borders, and the non-profit organization Builders Beyond Borders. The engineering department did not try to manage all aspects of this community development project. The technical engineering aspects were handled by engineers, while the funding, community organization, and materials acquisition was largely handled by other groups. This may serve as a model for other engineering departments interested in similar projects, but wary of the multidisciplinary responsibilities of undertaking such a project. This project is also one of the first of its kind to show in a qualitative and quantitative manner the increased educational impacts of international service-learning projects over traditional theoretical domestic design. 
International Journal for Service Learning in Engineering

Vol. 6, No. 2, pp. 98-117, Fall 2011

ISSN 1555-9033

\section{ACKNOWLEDGEMENT}

This project was supported by a number of organizations. We wish to thank the Pittsburgh Professional Chapter of Engineers Without Borders (EWB), the on-the-ground assistance from a Peace Corps Volunteer, additionally, funding for the majority of construction has been secured through matching grants from the Mayor of the province of Pujili, as well as from a US-based non-profit organization, Builders Beyond Borders. Additional funding was received from the University of Pittsburgh Mascaro Center for Sustainable Innovation (MCSI). 
International Journal for Service Learning in Engineering Vol. 6, No. 2, pp. 98-117, Fall 2011

ISSN 1555-9033

\section{REFERENCES}

1 Olson, L.E. and J.R. Goldberg, International Service Learning Senior Design Projects: Human Power and Medical Devices. 37th ASEE/IEEE Frontiers in Education Conference, 2007. Session F4B.

2 Wilson, D.M. and Y. Jones, Work In Progress - Integrated Service Learning on the Gulf Coast In the Hurricane Katrina Aftermath. 37th ASEE/IEEE Frontiers in Education Conference, 2007. Session F4B.

3 Campbell, R.C. and D. Wilson, Work in Progress - Integrating Humanitarian Course Modules into Engineering Coursework. 39th ASEE/IEEE Frontiers in Education Conference, 2009. Session T3G.

4 Backer, P. and B. Wei, Work in Progress-Recruiting Hispanic Students into Computing Through Community Service Learning. 40th ASEE/IEEE Frontiers in Education Conference, 2010. Session F4D.

5 Brenner, P.R., M. Schroeder, and G. Madey, Student Engineers Reaching Out: Case Studies in Service Learning and a Survey of Technical Need. 37th ASEE/IEEE Frontiers in Education Conference, 2007. Session T2J.

6 Carter, L., The Business of Service Learning. 39th ASEE/IEEE Frontiers in Education Conference, 2009. Session T3G.

7 Dinehart, D.W. and S.P. Gross, A Service Learning Structural Engineering Capstone Course and the Assessment of Technical and Non-technical Objectives. Advances in Engineering Education, 2010(Spring 2010).

8 Lima, M. and W. Oakes, Service-Learning Engineering in Your Community. 2006, St. Louis, MO: Great Lakes Press Inc.

9 Slowik, R., et al., Work in Progress - Description of a Service Learning Project to Design Assistive Technologies to Aid the Visually-Impaired in India. 39th ASEE/IEEE Frontiers in Education Conference, 2009. Session T3G.

10 Zydeck, L., Engineering Service Learning, Engineering Entrepreneurship and Assessment: Building a Program That Works. 40th ASEE/IEEE Frontiers in Education Conference, 2010. Session T2D.

11 Swan, C.W., K.G. Paterson, and A.R. Bielefeldt, Panel - Measuring the Impacts of Project-Based Service Learning in Engineering Education. 39th ASEE/IEEE Frontiers in Education Conference, 2009. Session M3B.

12 Aidoo, J., et al., International Design Project Experiences: Assessing The Short-Term Impact On Students. American Society for Engineering Education, 2007.

13 Budny, D., Lund, L., "Using Mobile Technology to Improve Course and Project Outcomes in a Service Learning Course for Freshman Engineering Students", Proceedings American Society for Engineering Education 2009 Annual Conference, Session 3230, Austin, TX, June 2009. Collier, Paul, The Bottom Billion: Why the Poorest Countries are Failing and What Can Be Done About It, Publisher: Oxford University Press, USA, ISBN-10: 0195311450, May 25, 2007. Collier, Paul, The Bottom Billion: Why the Poorest Countries are Failing and What Can Be Done About It, Publisher: Oxford University Press, USA, ISBN-10: 0195311450, May 25, 2007. William Easterly, The White Man's Burden: Why the West's Efforts to Aid the Rest Have Done So Much Ill and So Little Good, Penguin Publishing, ISBN: 1594200378, March 2006. Olson, L.E. and J.R. Goldberg, International Service Learning Senior Design Projects: Human Power and Medical Devices. 37th ASEE/IEEE Frontiers in Education Conference, 2007. Session F4B.

18 Swan, C.W., K.G. Paterson, and A.R. Bielefeldt, Panel - Measuring the Impacts of Project-Based Service Learning in Engineering Education. 39th ASEE/IEEE Frontiers in Education Conference, 2009. Session M3B. 
International Journal for Service Learning in Engineering Vol. 6, No. 2, pp. 98-117, Fall 2011

ISSN 1555-9033$$
\begin{aligned}
& \text { Fry, C.C. and G.W. Leman, Exposing Undergraduate Engineering and Computer Science Students to the } \\
& \text { Asian Business Culture in a Project-Based Abroad Program: An Assessment of Program Challenges. 38th }
\end{aligned}
$$$$
\text { ASEE/IEEE Frontiers in Edcation Conference, 2008. Session S4E. }
$$

Hanson, J.H., et al., Our First Experience with International Senior Design Projects - Lessons Learned.

2006 American Society for Engineering Education Annual Conference \& Exposition, 2006. Session 1315.

23 Johnson, P.E., et al., Motivation, Inspiration, and Economics of an International Service Project. Proceedings of the National Capstone Design Course Conference, 2007. O'Neill-Carrillo, E., et al., Mentoring Interdisciplinary Service Learning Projects. 37th ASEE/IEEE Frontiers in Education Conference, 2007. Session F4B.

Aidoo, J., et al., International Design Project Experiences: Assessing The Short-Term Impact On Students. American Society for Engineering Education, 2007.

Dyrud, M.A., Lessons Learned From An Integrated Senior Project. 33rd ASEE/IEEE Frontiers in Education Conference, 2003. Session S2B.

Blumenfeld, P.C., et al., Motivating project-based learning: Sustaining the doing, supporting the learning. Educational Psychologist, 1991. 26(3-4): p. 369-298.

The Engineer of 2020, ed. N.A.o. Engineering. 2004, Washington, D.C. : The National Academy Press.

Gabrielle, G.A., Advancing Engineering Education in a Flattened World. Journal of Engineering Education, 2005. Guest Editorial.

Coyle, Edward, Jamieson, Leah, Oakes,W., EPICS: Engineering Projects in Community Service, International Journal Engineering Education, VOl. 21, No. 1, 1995

Brenner, Paul R, Schroeder, Megan and Madey, Greg, Student Engineers Reaching Out: Case Studies in Service Learning and a Survey of Technical Need, ASEE/IEEE Frontiers in Education Conference, Oct. 2007. Session T2J

Campbell, R.C. and D. Wilson, Work in Progress - Integrating Humanitarian Course Modules into Engineering Coursework. 39th ASEE/IEEE Frontiers in Education Conference, 2009. Session T3G. Backer, P. and B. Wei, Work in Progress-Recruiting Hispanic Students into Computing Through Community Service Learning. 40th ASEE/IEEE Frontiers in Education Conference, 2010. Session F4D. Lima, M. and W. Oakes, Service-Learning Engineering in Your Community. 2006, St. Louis, MO: Great Lakes Press Inc.

Zydeck, L., Engineering Service Learning, Engineering Entrepreneurship and Assessment: Building a Program That Works. 40th ASEE/IEEE Frontiers in Education Conference, 2010. Session T2D.

Farkas, D. and N. Murthy, Internationalizing the Curriculum: Developing Travel Courses for Global Awareness. 38th ASEE/IEEE Frontiers in Edcation Conference, 2008. Session S4E.

Gerhardt, L.A. and R.N. Smith, Development of a Required International Experience for Undergraduate Engineering Students. 38th ASEE/IEEE Frontiers in Edcation Conference, 2008. Session S4E.

Gerhardt, Lester A. and Smith, Richard N. Development of a Required International Experience for Undergraduate Engineering Students, ASEE/IEEE Frontiers in Education Conference, Oct. 2008. Session S4E.

Athreya, Krishna S. Rover, Walter, Mickelson, McGrath, Kalkhoff, Rasmussen, Starns, Wiley-Jones, Saunders, Shelley, Work In Progress - Progression of an Engineering Leadership Program for the Future, ASEE/IEEE Frontiers in Education Conference, Oct. 2007. Session T2J

Dinehart, David W. and Gross, Shawn P. A Service Learning Structural Engineering Capstone Course and the Assessment of Technical and Non-technical Objectives, Journal Advances in Engineering Education, ASEE, Spring 2010. 
Jewell, Thomas K. and Spinelli, John M, Globalization of the Union College Engineering Programs, ASEE/IEEE Frontiers in Education Conference, Oct. 2008. Session S4E.

Cynthia C. Fry, and Gregory W. Leman, Exposing Undergraduate Engineering and Computer Science Students to the Asian Business Culture in a Project-Based Abroad Program: An Assessment of Program Challenges, ASEE/IEEE Frontiers in Education Conference, Oct. 2008. Session S4E.

41 Daniel Farkas, Narayan Murthy, Internationalizing the Curriculum: Developing Travel Courses for Global Awareness, ASEE/IEEE Frontiers in Education Conference, Oct. 2008. Session S4E.

42 Walther, Joachim, Kellam, Nadia, Radcliffe, David, Chantinee Boonchai, Integrating Students' Learning Experiences through Deliberate Reflective Practice, ASEE/IEEE Frontiers in Education Conference, Oct. 2009. Session T3G.

Hogan, C., Creative and reflective journal processes. The Learning Organization, 1995. 2(2). Athreya, K.S., et al., Work In Progress - Progression of an Engineering Leadership Program for the Future. 37th ASEE/IEEE Frontiers in Education Conference, 2007. Session T2J.

45 Carberry, A.R., Work in Progress - Assessing Engineering Service Students' Characteristics. 40th ASEE/IEEE Frontiers in Education Conference, 2010. Session T2D.

46

Commission, A.A., Criteria for Accrediting Engineering Programs. 2008, ABET, Inc.: Baltimore, MD. 